\title{
UK TOURISM ARRIVALS AND DEPARTURES: SEASONALITY, PERSISTENCE AND TIME TRENDS
}

\author{
Luis A. Gil-Alana, University of Navarra, Pamplona, Spain and University \\ Francisco de Vitoria, Madrid, Spain \\ José L. Ruiz-Alba, University of Westminster, London, United Kingdom \\ Raquel Ayestarán, University Francisco de Vitoria, Madrid, Spain
}

\begin{abstract}
Issues such as seasonality, persistence and trends are examined in the series referring to the number of UK arrivals and departures using techniques based on fractional integration. This methodology is much more flexible than others based on integer degrees of differentiation and permits us to describe in a more general way the effects of shocks in the series. Our results indicate that the series display significant time trends; they show high persistence with orders of integration in the fractional range, thus showing longlasting effects of shocks; seasonality is an important issue, and in removing the seasonality through seasonal differentiation, the time trends disappear though persistence remains as a relevant feature of the data. Policy implications of the results obtained are displayed at the end of the article.
\end{abstract}

Keywords: Seasonality; UK tourism; time series

JEL Classification: C22; M3; L83

\author{
Corresponding author: Luis A. Gil-Alana \\ University of Navarra \\ Faculty of Economics and NCID \\ 31080 Pamplona \\ SPAIN
}

Email: alana@unav.es

Luis A. Gil-Alana gratefully acknowledges financial support from the Ministerio de Ciencia, Innovación y Universidades (ECO2017-85503-R). The Fundacion Francisco de Vitoria is also acknowledged. Comments from the Editor and an anonymous reviewer is gratefully acknowledged. 


\section{Introduction}

The prediction of future flows of tourist visitors is critical; consequently, scholars, policy makers and managers have dedicated efforts to understand the undulations in tourism growth cycles and demand (Song, Qiu \& Park, 2019). In fact, since the 50s, there have been many studies investigating what affects the flows of international tourism (Chu, 1998). The prediction of tourism demand is gaining interest for many reasons, but mainly due to fact that more tourist destination/countries are competing for limited resources (Lim, 2006). This competition is clear, because, although Europe still represents $52 \%$ of global tourist arrivals, other areas, such as Asia and the Pacific and Africa, are growing more (UNWTO 2014). Key elements to understand tourism demand behaviour are seasonality, persistence and trends in travellers.

This study analyses the seasonal effects and the level of persistence of overseas visitors to the UK and of UK visitors abroad applying a framework that uses fractional integration in the analysis of (monthly) data from a period that runs from January 1980 to October 2018, with a total of 466 monthly observations for each series. These two features (seasonality and persistence) are very commonly observed in tourism series and, although there is a large variety of approaches to model them, there is not consensus about which one is the most appropriate, sometimes depending on the data themselves. According to Gil-Alana (2005), seasonality can be modelled either using deterministic methods (by means of seasonal dummy variables) or using stochastic methods, and, in the latter case, the most common approaches are by means of seasonal stationary (ARMA) models or using nonstationary seasonal differentiation. Determining which one of these approaches is more appropriate can be done by using, for example, the tests of Dickey, Hasza and Fuller (1984), Hylleberg, Engle, Granger and Yoo et al. (1990), or 
Beaulieu and Miron (1993) among many others. Applications using these methods include, among others, Kim and Moosa (2001), Alleyne (2006), Shen et al. (2009), Lim and Chan (2009), Chang et al. (2009), Hepsag (2016), etc. On the other hand, persistence is another common feature in tourism, and a battery of non-seasonal unit roots have been applied to determine if shocks have permanent, long lasting or transitory effects (Narayan, 2003; 2005a,b; Saleh et al., 2011; Bassil et al., 2014; Tan and Tan, 2014; Perles-Ribes et al., 2016; etc).

This paper departs from the above approaches in the sense that we consider the possibility of fractional differentiation. This is a much more flexible approach that permits us to differentiate the cases of mean reversion from those with no mean reversion as well as the persistence and long-lasting effects of the shocks based fundamentally on the value of this differencing parameter. This methodology has been already applied in tourism. Examples are the papers by Cunado et al. (2004), Chu (2008), Nowman and Van Dellen (2012), Chen and Malinda (2014), Gil-Alana et al. (2014), Al-Shboul and Anwar (2017), Tung et al. (2017), Gil-Alana and Huijbens (2018), Gil-Alana, Figueiredo and Wanke (2019), Perez-Rodriguez and Santana-Gallego (2020), etc. However, unlike most of these papers, fractional differentiation is used here in the context of seasonality and linear time trends, looking thus at the three issues (persistence, seasonality and time trends) in a unified treatment. This is in fact the main methodological contribution of this work.

From an empirical viewpoint, as far as we know, this is the first paper that use long memory fractionally integrated methods in the analysis of UK tourism data. The UK ranked sixth in the UNWTO international tourist arrivals league in 2016, behind France, the USA, Spain, China and Italy and a high proportion of visits to the UK are repeat visits (77\%) and business visits are more likely to be repeat visits (92\%) (Visit Britain, 2015). 
For many countries, monthly arrivals happen through the year and seasonality represents one of the industry's main problem (Roselló-Nadal, Riera-Font \& Sansó-Roselló, 2004), this being considered as an uneven distribution of the number of tourists throughout the year that can also return to recurrent stability (Vergori, 2012). Seasonality is also important in the UK as most holiday tourists visit Britain during the warmest months from April to September; however, business visitors are spread evenly through the seasons and more likely in Q2 and Q4 (Visit Britain, 2015). In June 2016, the UK voted to leave the EU in a referendum. There is still uncertainty about the kind of deal and circumstances under which the UK will leave the EU and what consequences this potential exit will have for the economy and, in particular, for tourism. Brexit is a huge challenge; therefore, it is crucial to know to what extent this impact will be transitory or whether it will remain for the long term.

In that sense, the use of time series models in the analysis of tourism demand can help us to answer some of the above questions (Song, Qiu \& Park, 2019). Following that paper, this study belongs to the category of explorative methods in time series using updated techniques based on long range dependence models.

As earlier mentioned, we investigated the number of overseas visitors to the UK and of UK visitors abroad. These series present several features that deserve our attention: firstly, the series are highly persistent and this is a feature that we analyse in these data by using fractionally integrated methods. Secondly, seasonality is another important feature that will be examined. In fact, seasonality has been acknowledged as a key element for tourism demand forecasting (Song \& Li, 2008). Finally, the presence of deterministic trends in the data is another issue that will be examined in this work. All these features will be jointly examined in this paper in a single framework that use fractional integration with deterministic trends and seasonal autoregressions. 
The main results in this work show significant time trend coefficients and a high level of dependence in the series, and there is also a high level of seasonality. Once these effects have been determined and identified, we will study its causes and consequences in the event of exogenous shocks affecting the series. The level of persistence is identified by means of fractional integration techniques and one important result in this work is that the integration orders of the series are fractional, being significantly different from zero and one, which are the values more studied in the literature. Moreover, a higher persistence is found in the case of the UK departures than in the OS arrivals, implying longer effects of shocks in the former than in the latter series. With respect to the seasonality, once this is removed throughout seasonal differentiation, the time trends become statistically insignificant, though the series remain highly persistent. Some implications of these results are presented in the concluding sections.

Section 2 presents a review on the modelization on tourist arrivals and UK visits abroad. Section 3 focuses on the methods employed in the paper and Section 4 describes the series. Next we present the empirical results in Section 5, while Section 6 concludes the paper.

\section{A review of the literature}

Methods based on unit roots have been widely employed in tourism when modelling time series. Thus, for example, seasonal unit roots have been employed to analyse the intrayear variation in arrivals to the Balearic Islands (Roselló-Nadal, Riera-Font \& SansóRoselló, 2004). Most of studies have applied conventional unit root tests (Narayan, 2003; 2005a,b, Lean \& Smyth, 2008, 2009; Tang, 2011; Fuleky et al., 2014; etc.) which focus uniquely on the $\mathrm{I}(0) / \mathrm{I}(1)$ dichotomy and do not take into account fractionally integrated alternatives. This is a clear shortcoming noting that it has been shown that all standard 
unit roots methods present very low power if the alternatives include fractional integration (Diebold \& Rudebusch, 1991; Hassler Wolters, 1994; etc.).

Thus, fractional differentiation has become very popular in the analysis of tourism data, based on its higher degree of flexibility, noting that models based on unit roots are simply very specific cases of the former models when the order of integration is 1 . Applications of fractional integration in tourism include, for instance, the work by GilAlana, Perez de Gracia and Cunado (2004) who deals with seasonal fractional integration in the analysis of the Spanish quarterly tourism series. They found orders of integration in the range $(0,1)$ supporting thus seasonal long memory features. In Gil-Alana (2005) the author focusses on the number of tourist arrivals to the USA, finding evidence of a strong degree of persistence in the data; Chu (2008) employed fractionally integrated ARMA (ARFIMA) model to analysis tourism demand in Singapore finding that this model outperforms others in terms of forecasting; Assaf, Barros and Gil-Alana (2011) used a variety of I(d) models in the analysis of tourist arrivals in Australia and found that the most accurate model was the one allowing for non-seasonal and seasonal features; Nowman and Van Dellen (2012) also used an ARFIMA model in the analysis of UK overseas visitors, while Chen and Malinda (2014) incorporated structural breaks in the analysis of the long memory features of the returns of travel and tourism indices for various European countries along with New Zeeland and the US. Al-Shboul and Anwar (2017) who studied long memory features in tourist arrivals to Singapore and confirmed its presence in long-term tourist destination; and Cellini and Cuccia (2013) who studied museum visits in Italy and the role of cultural attractions as a means to mitigate seasonality in tourism. More recently, Lanouar and Goaied (2019) studied the impact of terrorism on tourist arrivals to Tunisia using seasonality, unit roots, breaks and long memory behaviour and they analysed transitory and permanent shock on tourism demand. 
Other applications using these long memory techniques in tourism data include the papers by Chokethaworn et al. (2010), Gil-Alana, Mudida and Perez de Gracia (2014), AlShboul and Anwar (2017), Tung et al. (2017), Gil-Alana and Huijbens (2018) and GilAlana, Figueiredo and Wanke (2019).

\section{Methodology}

A very common way to measure the degree of persistence in time series data is by looking at the autoregressive coefficient $\rho$ in an autoregressive model of order 1, i.e., AR(1), of the form:

$$
(1-\rho B) x_{t}=\varepsilon_{t}, \quad t=1,2, \ldots,
$$

where $\mathrm{x}_{\mathrm{t}}$ is the observed time series, $\mathrm{B}$ is the backshift operator $\left(\mathrm{B} \mathrm{x}_{\mathrm{t}}=\mathrm{x}_{\mathrm{t}-1}\right)$ and $\varepsilon_{t}$ is a white noise process. Thus, the higher the value of $\rho$ in equation (1) is, the higher the degree of dependence/persistence in the observed data. Other authors have extended this model to a general $\mathrm{AR}(\mathrm{p})$ process:

$$
\phi_{p}(B) x_{t}=\varepsilon_{t}, \quad t=1,2, \ldots,
$$

where $\varphi_{\mathrm{p}}(\mathrm{B})=\left(1-\varphi_{1} \mathrm{~B}-\ldots-\varphi_{\mathrm{p}} \mathrm{B}^{\mathrm{p}}\right)$, and they measure persistence as the sum of the AR coefficients, i.e.,

$$
\sum_{j=1}^{p} \phi_{j}
$$

These measures, however, assume that the underlying process $\mathrm{x}_{\mathrm{t}}$ is stationary $\mathrm{I}(0)$ as opposed to the nonstationary I(1) case that might occur when the AR coefficient(s) is (are) close to 1 . Thus, all the standard measures of persistence are based on the $\mathrm{I}(0) / \mathrm{I}(1)$ cases, and a large number of test statistics have been proposed and improved in the last 
thirty years to determine if the series are $\mathrm{I}(0)$ stationary or I(1) nonstationary. ${ }^{1}$ Moreover, this distinction is important to clarity the duration of the shocks. Thus, these have a transitory nature under stationarity $\mathrm{I}(0)$ but they will have permanent effects in the unit root or $\mathrm{I}(1)$ case.

Nevertheless, the $\mathrm{I}(0)$ and the $\mathrm{I}(1)$ specifications are both specific cases of a more general class of models, denominated fractional integration, which means that the number of differences to be taken in a series to render it as a stationary $I(0)$ is potentially a fractional value. Thus, a process $x_{t}$ is integrated of order $d$, and is denoted as $I(d)$, if it admits the following representation:

$$
(1-B)^{d} x_{t}=u_{t}, \quad t=0, \pm 1, \ldots
$$

where $u_{t}$ is supposed to be $I(0)$ and it may be specified in terms of (1) or (2) (i.e., replacing $\mathrm{x}_{\mathrm{t}}$ by $\mathrm{u}_{\mathrm{t}}$ in the two equations). Thus, the $\mathrm{I}(\mathrm{d})$ specification incorporates the two commonly employed cases in the literature, that is, the stationary $\mathrm{I}(0)$ model if $\mathrm{d}=0$ and the unit root approach when $d=1$. At this point it is worth noticing that the term $(1-L)^{d}$ in the left hand side of equation (3) can be expanded through a Binominal expansion, such that:

$$
(1-B)^{d}=\sum_{j=0}^{\infty}\left(\begin{array}{l}
d \\
j
\end{array}\right)(-1)^{j} B^{j}=1-d B+\frac{d(d-1)}{2} B^{2}-\ldots
$$

for all real $\mathrm{d}$, and, as a consequence, we obtain that $\mathrm{x}_{\mathrm{t}}$ in (3) can be expressed in terms of all its past history, i.e.

$$
x_{t}=d x_{t-1}-\frac{d(d-1)}{2} x_{t-2}+\ldots+u_{t} \text {. }
$$

Based on (4), the higher the d, the higher the association between the observations and more dependence and persistence in the data. In the application carried out in Section

\footnotetext{
${ }^{1}$ Some authors also consider the possibility of $\mathrm{I}(2)$ processes, for instance, in certain types of prices (Georgoutsos and Kouretas, 2004; Di Iorio et al., 2016; etc.).
} 
5, this model is employed assuming that $\mathrm{x}_{\mathrm{t}}$ are not the observed data but the errors in a linear regression model of the following form:

$$
\mathrm{y}_{\mathrm{t}}=\alpha+\beta \mathrm{t}+\mathrm{x}_{\mathrm{t}}, \quad \mathrm{t}=1,2, \ldots
$$

where $\alpha$ and $\beta$ are coefficients which are unknown and therefore will be estimated from the data along with the estimate of $\mathrm{d}$. In addition, based on the monthly nature of the data under investigation, and given the strong seasonal pattern observed in Figure 1 below, we model this pattern by means of using a seasonal autoregression of order 1 model in the ddifferenced process,

$$
\left(1-\rho_{s} B^{12}\right) u_{t}=\varepsilon_{t}, \quad t=1,2, \ldots
$$

where the coefficient $\rho_{\mathrm{s}}$ refers to the seasonal AR component. ${ }^{2}$

The estimation is carried out by using a parametric method that uses the frequency domain version of the Whittle function, originally proposed in Dahlhaus (1989), and implemented in our case by using a version of a testing method due to Robinson (1994). This approach is very convenient in the context of the nonstationary data used in this application. ${ }^{3}$

\section{Data description}

Data were collected from the Office of National Statistics (ONS) in the UK. Two series were used: a) Arrivals from overseas (OS Arrivals); b) UK visitors abroad (UK Departures). In total, there were 466 monthly observations for each series, comprising the period from January 1980 to October 2018.

\section{[Figure 1 here]}

\footnotetext{
2 Alternatively, we could have employed a seasonal long memory model of the form advocated, for example, in Gil-Alana and Robinson (2001). In such a case, we would replace (1-B) ${ }^{\mathrm{d}}$ in equation (3) by (1$\left.\mathrm{B}^{12}\right)^{\mathrm{d}}$.

${ }^{3}$ The version of the tests of Robinson (1994) used in this work tests any real value d, including thus values in the nonstationary range $(\mathrm{d} \geq 0.5)$.
} 


\section{Empirical results}

Using equations (5), (3) and (6), we examine the model,

$$
y_{t}=\alpha+\beta t+x_{t}, \quad(1-B)^{d} x_{t}=u_{t}, \quad\left(1-\rho_{s} B^{12}\right) u_{t}=\varepsilon_{t},
$$

where $\mathrm{y}_{\mathrm{t}}$ is the observed series corresponding to the overseas visits to the UK and UK visitors abroad, as well as their log-transformed values, $\beta$ describes the underlying trend in the data, $d$ is the differencing parameter, related to the degree of persistence and $\rho_{\mathrm{s}}$ is the seasonal AR coefficient.

Three scenarios are considered in the results presented in Table 1. They correspond to the estimated values of d: firstly, in the second column, we suppose that there are no deterministic terms, and thus, we impose $\alpha=\beta=0$ a priori in (7); in the second scenario (third column) an intercept is included, and thus, $\beta=0$ a priori, while in the third one (fourth column) a liner time trend is estimated along with the degree of persistence.

\section{[Tables 1 - 2 here]}

Several things are remarkable in Table 1. First, the trend coefficient is statistically significant in the four cases, and the estimated degrees of persistence, i.e., the d-values are in the four series strictly higher than 0 and smaller than 1 , the values ranging between 0.38 (OS Arrivals to the UK) and 0.53 (Log of UK departures). The estimated coefficients for each series are given in Table 2. We see that the time trend coefficient is higher for the UK visitors abroad than for the overseas arrivals to the UK, and the same happens in case of the log-transformed data. Dealing with the seasonality, we see that the seasonal AR coefficient is very high in all cases, being very close to 1 . Due to this, seasonal unit root tests (based on both Dickey, Hasza and Fuller, 1984 and Hylleberg, Granger, Engle and Yoo, 1990 methods) were also performed and obtained in the two cases strong 
support of seasonal unit roots. Thus, seasonal first differences were performed, and the series are presented in Figure $2 .{ }^{4}$

[Figure 2 here]

Based on the seasonal differenced series, we estimate now the parameters in a new model that is formed by using exclusively equations (5) and (3), i.e.

$$
y_{t}=\alpha+\beta t+x_{t}, \quad(1-B)^{d} x_{t}=u_{t},
$$

assuming now that $\mathrm{u}_{\mathrm{t}}$ in (8) is a white noise process (in Table 3) and autocorrelated (in Table 4). For the latter case, we can impose a simple AR(1) process as in (1) noting that seasonality has been removed throughout the differencing process. However, instead of that, we use a nonparametric approach which produces autocorrelation values that also decay exponentially as in the AR processes. This approach is in accordance to Bloomfield (1973) and is called non-parametric due to the fact that it is only implicitly defined by the formula of its spectral density function:

$$
f(\lambda ; \tau)=\frac{\sigma^{2}}{2 \pi} \exp \left(2 \sum_{r=1}^{m} \tau_{r} \cos (\lambda r)\right),
$$

where $\sigma^{2}$ is the error term variance and $m$ is the parameter referring to the short-run components. Bloomfield (1973) showed that equation (9) approximated very well the spectral density function of a highly parameterized AutoRegressive Moving Average (ARMA) model, with the autocorrelations decaying also exponentially, and with the additional property that the model is stationary across all its range of values unlike what happens in the AR case.

\section{[Tables 3 - 4 here]}

\footnotetext{
4 The fact that seasonal unit roots were unrejected implies that seasonal differentiation is sufficient to describe this component, with no need of a more general seasonal long memory model as the one used in Gil-Alana et al. (2004).
} 
Table 3 displays the estimates under the assumption of white noise errors. The values of $d$ are once more in the interval $(0,1)$ supporting fractional integration, ranging now between 0.34 (Log of UK Departures) and 0.38 (UK Departures), and, allowing for autocorrelation (through the Bloomfield model, in Table 4) the values are slightly higher, but still in the range $(0,1)$ constrained now between 0.47 (OS Arrivals) and 0.62 (UK Visitors Departures).

\section{Concluding comments}

Tourism is one of the fastest growing global industries and this requires more accurate forecasts of tourism demand (Claveria \& Torra, 2014). The goal in this work was to examine several features observed in UK departures and arrivals from a new time series perspective. We describe these main features (which are basically seasonality, persistence and trends) with techniques which are based on the concepts of long run dependence and fractional integration. This methodology is very appropriate, primarily because it is more general than other more classical methods, which are based on integer values for the order of differentiation, i.e., zero in case of stationary series and one for nonstationary ones. This paper contributes from a methodological perspective by using updated techniques in time series analysis based on fractional integration and long memory models, and also in terms of specific findings regarding tourism in the UK, one of the major destinations in the world.

Some of the main findings regarding tourism in the UK are: 1) there is a significant positive linear trend; 2) seasonality is very relevant; 3) persistence is a third important issue, with shocks having transitory though long-lasting effects. Dealing with the deseasonalised data, the trend becomes then statistically insignificant although the persistence remains as a very important feature in the data. In general, shocks will be 
transitory and the process of recovery seems to be faster with the overseas visitors than with the UK visitors abroad based on the higher degree of integration observed in the latter series. It is noteworthy to highlight that the growth in tourist visitors happens only in seasonal periods. Therefore, the UK authorities should focus not on seasonal periods that are growing, but in particular in non-seasonal periods that are not growing.

\section{Contributions to theory}

A relevant contribution of this paper is to find that the integration orders of the series (OS Arrivals and UK Departures and their log-transformations) are all fractionally integrated with values constrained between 0 and 1 and, thus, supporting the idea of fractional integration and mean reverting behaviour. A linear time trend was also found in all cases. These fractional orders of integration are slightly higher for UK visits than for OS Arrivals implying that shocks have longer lasting effects in the former than in the latter series. In any case, in all cases, shocks will have transitory effects, returning after a shock to their original long-term projections.

Another relevant result is that seasonality matters in all cases, with a seasonal AR coefficient very close to 1 in the four series. Performing seasonal unit root tests, evidence was found in favour of seasonal integration, and removing seasonality throughout seasonal differentiation, fractional degrees of integration were still found in the four series although the time trends were now insignificant in all cases.

\section{Contributions to practice}

This study has some contributions for practitioners. Thus, for example, based on the fact that there is not a trend in the deseasonalized data, it seems to imply that the increase in the number of visitors to and from the UK is increasing mainly during the seasonal 
periods; thus, it is relevant to incentivise tourism in non-seasonal periods. The factors responsible for seasonality are climate, school holidays, or special events, and authors such as Roselló-Nadal, Riera-Font \& Sansó-Roselló, (2004) suggested that governments could limit their efforts at mitigating these effects by proposing special strategic marketing initiatives for the creation of new offers in seasonal periods.

Firstly, policy makers could use seasonal segmentation and, in particular, make greater efforts to promote attracting business travelers to the UK. They can work closely with tour operators to focus their efforts on non-peak seasons. In that sense, in line with Lim and McAleer (2001) who mention events, festivals, fairs and conferences, the promotion of business travellers could be also considered as a wise strategy. However, they should consider that attracting business travellers has a moderate impact on reducing seasonality, particularly in urban areas (Saito and Romao, 2018).

Secondly, Destination Marketing Organizations (DMOs) could consider that this has implications for marketing promotion, and planning the tourism supply of transport and other services (Lim \& McAleer, 2001), and obviously this has an effect on the hotel industry and HORECA sector. For outside the peak seasons, Vergori (2012) suggests new forms of tourism, such as cultural or wine-and-food and experience tourism.

Thirdly, apart from the traditional pricing strategies for non-peak seasons (CapóParrilla, Riera-Font \& Roselló-Nadal, 2007), the hotel sector could dedicate greater efforts to estimate the demand and to generate it with more sophisticated strategies such as the estimation of the values of the degree of dependence in tourist arrivals can contribute to the development of effective tourism marketing strategies (Al-Shboul \& Anwar, 2017).

From the point of view of policy makers whose task is to design appropriate policy responses to exogenous shocks, the fact that the integration orders are found to be smaller 
than 1 in all cases suggests that shocks will be transitory, although with long-lasting effects, and such evidence should inform tourism policies. Policy makers can anticipate future trends and develop tourism marketing strategies. This study has also insightful contributions for Destination Management Organisations (DMOs) and also for policy makers. In particular, we see huge implications for the city of London that plays a leading role in business travelling activities in MICE segment (Meetings, Incentives, Conferencing and Exhibitions). City Hall, Government, professional bodies, and similar actors, could take advantage of our study and gain a deeper understanding in relation to the opportunities and challenges derived from seasonality that directly affects capacity and can help them to focus on special marketing strategies in order to attract demand based on dynamic pricing and targeting specific emisor segments of B2B activities like business travellers.

\section{Limitations and future research}

One limitation is that, being that the Brexit process is a unique phenomenon, the conclusions in terms of generalisation are limited. Another possible limitation comes from the fact that, in order to estimate tourism demand, researchers contemplate one or some of these three parameters: tourist arrivals, tourist expenditure and length of stay (Song, Qui \& Park, 2019). For the purpose of this paper, only the flow of visitors has been investigated, following the line of research on modelization of tourism arrivals (Shareef and McAleer, 2007; Katircioglu, 2009; Nejad and Tularam, 2010; Poprawe, 2015; Balli et al., 2019; Rosselló-Nadal and Jianan, 2020; etc.). Future studies could also incorporate one or two of the other elements. Another limitation is that this paper has not considered the origin country of the visitors to the UK; this could be addressed in future studies and provide deeper insights and more specific conclusions. Future research could 
investigate the impact of Brexit on tourist demand to the UK. Brexit has meant a weakening of the British pound against the euro, which benefits attracting visitors to the UK, but some studies have shown that the exchange rate seems to increase seasonality as the more it benefits tourists, the more they tend to come during the peak season (RosellóNadal, Riera-Font \& Sansó-Roselló, 2004). Therefore, although, potentially, Brexit could benefit tourism in the UK, it could also increase the problem of seasonality. Few studies have investigated the quantitative impact of seasonality on business tourism management (Park, Yaduma, Lockwood, \& Williams, 2016; Saito \& Romao, 2018). Another potential line of research could focus on regional (arrivals and departure) data, comparing the results for long haul (interregional) and short haul (intraregional) data in the UK using the same techniques as those used in this work. Further research should also consider the issues of forecasting in these series though since the hypothesis of integer differentiation is clearly rejected for these data in favour of fractional integration, we should also expect better results with the $\mathrm{I}(\mathrm{d})$ models in the forecasting results. 


\section{References}

Alleyne, D. (2006), 'Can seasonal unit root testing improve the forecasting accuracy of tourist arrivals?', Tourism Economics 12, pp 45-64.

Al-Shboul, M \& Anwar, S. (2017), Long memory behaviour in Singapore's tourism market, International Journal of Tourism Research 19, 5, 524-534.

Allcock, J. B. 1989 Seasonality. In Tourism Marketing and Management Handbook, S.

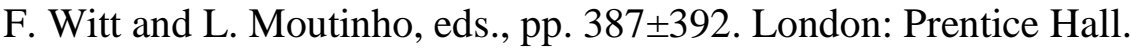

Assaf, A.G., C.P. Barros and L.A. Gil-Alana (2011), Persistence in short and long term tourist arrivals in Australia, Journal of Travel Research 50, 2.

Balli, H.O., W.H.K. Tsui and F. Balli (2019), Modelling the volatility of international visitor arrivals to New Zealand, Journal of Air Transport Management 75, 204-214

Bassil, C., S. Anwar and A.S. Saleh (2014), Is Tourism in Lebanon Subject to Permanent or Transitory Exogenous Shocks?, Tourism Analysis 19, 6.

Beaulieu, J.J. and J.A. Miron (1993), Seasonal unit roots in aggregate US data, Journal of Econometrics 55, 1, 305-328.

Bloomfield, P. 1973. An exponential model in the spectrum of a scalar time series. Biometrika, 60, 217-226.

Capó-Parrilla, J., Riera-Font, A., and J. Roselló-Nadal (2007). Accommodation determinants of seasonal patterns. Annals of Tourism Research, 34, 422-436.

Cellini, R. and T. Cuccia (2013). Museum and monument attendance and tourism flow: A time series analysis approach. Applied Economics, 45(24), 3473-3482.

Chang, C-L, S. Sriboonchitta, and A. Wiboonpongse (2009). Modelling and forecasting tourism from East Asia to Thailand under temporal and spatial aggregation. Mathematics and Computers in Simulation, 79, 5, 1730-1744.

Chen, J.H. and M. Malinda (2014), Long memory and multiple structural breaks in the returns of travel and tourism indices, Journal of Business and Economics 5, 9, 14601472.

Chokethaworn, K., J. Sriboonjit, C. Chaiboonsri and P. Chaitip (2010), An empirical approach to the evaluation of international tourists' expenditures in Thailand using the ARFIMA-FIGARCH model, International Journal of Business Research 10, 1, 141.

Chu, F. L. (1998). Forecasting tourism demand in Asian-Pacific countries. Annals of Tourism Research, 25(3), 597-615

Chu, F.-L. (2008). A Fractional Integrated Autoregressive Moving Average Approach to Forecasting Tourism Demand. Tourism Management, 29: 79-88. 
Claveria, O. and Torra, S., 2014. Forecasting tourism demand to Catalonia: Neural networks vs. time series models. Economic Modelling, 36, pp.220-228.

Cunado, J., L.A. Gil-Alana and F. Perez de Gracia, 2004, Seasonal fractional integration in the Spanish tourism quarterly time series, Journal of Travel Research 42, 4, 408-414.

Dahlhaus, R., 1989, Efficient parameter estimation for self-similar processes, Annals of Statistics 17, 1749-1766.

Dickey, D.A., D.P. Hasza and W.A Fuller, 1984, Testing for unit roots in seasonal time series, Journal of the American Statistical Association 79, 386, 355-367.

Diebold, F.X. \& Rudebusch, G.D. 1991, 'On the power of Dickey-Fuller test against fractional alternatives', Economics Letters, vol.35, no.1, pp.155-160.

Di Iorio, F., S. Fachin and R. Lucchetti (2016), Can you do the wrong thing and still be right? Hypothesis testing in I(2) and near I(2) cointegrated VARs, Applied Economics $48,38,3665-3678$.

Fuleky, P., Q. Zhao and C.S. Bonham, 2014, Estimating demand elasticities in nonstationary panels. The case of Hawaii tourism, Annals of Tourism Research 44, 131142.

Georgoutsos, D.A. and G.P. Kouretas (2004), A multivariate I(2) cointegration analysis of German hyperinflation, Applied Financial Economics 14, 1, 29-41.

Gil-Alana, L.A. (2005). Modelling international monthly arrivals using seasonal univariate long-memory processes. Tourism Management, 26(6), 867-878.

Gil-Alana, L.A. (2005), Deterministic seasonality versus seasonal fractional integration, Journal of Statistical Planning and Inference 134, 2, 445-461.

Gil-Alana, L.A., O.H.S. Figueiredo and P. Wanke (2019), Structural breaks in Brazilian tourism revenues: Unveiling the impact of exchange rates and sports mega-events, Tourism Management 74, 207-211.

Gil-Alana, L. A., \& Huijbens, E. H. (2018). Tourism in Iceland: Persistence and seasonality. Annals of Tourism Research, 68, 20-29.

Gil-Alana, L.A., Mudida, R, and F. Perez de Gracia (2014), Persistence, long memory and seasonality in Kenyan tourism series, Annals of Tourism Research 46, 89-101.

Gil-Alana, L.A., F. Perez de Gracia and J. Cunado, 2004, Modelling monthly Spanish tourism: A seasonal fractionally integrated approach, Tourism Economics 10, 1, 79-94.

Gil-Alana, L.A. and P.M. Robinson (1997). Testing of unit roots and other nonstationary hypotheses in macroeconomic time series, Journal of Econometrics 80, 241-268.

Hasslers, U. \& J. Wolters 1994, 'On the power of unit root tests against fractional alternatives', Economics Letters vol.45, no. 1, pp.1-5. 
Hepsag, A. (2016), Testing convergence of tourist markets: evidence from seasonal unit roots tests, Anatolia, An International Journal of Tourism and Hospitality Research 27, 2.

Hylleberg, S., R.F. Engle, C.W.J. Granger and B.S. Yoo, (1990) Seasonal integration and cointegration, Journal of Econometrics, 44, (1,2), 215-238.

Katircioglu, S. (2009), Tourism, trade and growth: the case of Cyprus, Applied Economics 41, 21, 2741-2750.

Kim, J.H., and Moosa, I. (2001), 'Seasonal behaviour of monthly international tourist flows: specification and implications for forecasting models', Tourism Economics 7, 381-396.

Kwiatkowski D, P.C.D Phillips, P. Schmidt, Y. Shin, (1992), Testing the null hypothesis of stationarity against the alternative of a unit root: How sure are we that economic time series have a unit root?, Journal of Econometrics 54, 159-178.

Lanouar, C. and M. Goaied (2019). Tourism, terrorism and political violence in Tunisia: Evidence from Markov-switching models. Tourism Management, 70, 404-418.

Lean, H.H. and R. Smyth, 2008, Are Malaysia's tourism market converging? Evidence from univariate and panel unit root tests with structural breaks, Tourism Economics 14, 1.

Lean, H. H., \& Smyth, R. (2009). Asian financial crisis, avian flu and terrorist threats: Are shocks to Malaysian tourist arrivals permanent or transitory? Asia Pacific Journal of Tourism Research, 14(3), 301-321.

Lim, C. (2006). A survey of tourism demand modelling practice: Issues and implications. In L. Dwyer, \& P. Forsyth (Eds.). International handbook on the economics of tourism (pp. 45-72). Cheltenham: Edward Elgar Publishing. Lim, C., \& McAleer, M. (2000). A seasonal analysis of Asian tourist.

Lim, C. and F. Chan (2009). Forecasting tourist accommodation demand in New Zealand. 18th World IMACS / MODSIM Congress,13-17 July, (2009), Cairns, Australia. Available on Website. http://mssanz.org.au/modsim09.

Lim, C., \& McAleer, M. (2001). Monthly seasonal variations: Asian tourism to Australia. Annals of Tourism Research, 28(1), 68-82.

Narayan, P.K., 2003, Tourism demand modelling: some issues regarding unit roots, cointegration and diagnostic tests, International Journal of Tourism Research 5, 5, 369380 . 
Narayan, P.K., 2005a, Testing the Unit Root Hypothesis When the Alternative is a Trend Break Stationary Process: An Application to Tourist Arrivals in Fiji, Tourism Economics 11,3 .

Narayan, P.K., 2005b, The Structure of Tourist Expenditure in Fiji: Evidence from Unit Root Structural Break Tests, Applied Economics 27, 10, 1157-1161.

Nejad, S.A.H.S. and A. Tularam, (2010), Modeling Tourist Arrivals in Destination Countries: An Application to Australian Tourism, Journal of Mathematics and Statistics $6(4)$.

Nowman, K.B. and Van Dellen, S. 2012. Forecasting overseas visitors into the United Kingdom using continuous time and autoregressive fractional integrated moving average models with discrete data. Tourism Economics. 18 (4), 835-844.

Park, S., Yaduma, N., Lockwood, A., \& Williams, A. (2016). Demand fluctuations, labour flexibility and productivity. Annals of Tourism Research, 59, 93-112.

Perez-Rodriguez, J.V. and M. Santana-Gallego (2020), Modelling tourism receipts and associated risks, using long-range dependence models, Tourism Economics, forthcoming.

Perles-Ribes, J.F., A.B. Ramón-Rodriguez, A. Rubia-Serrano and L. Moreno-Izquierdo, (2016), Economic crisis and tourism competitiveness in Spain. Permanent effects or transitory effects, Current Issues in Tourism 19, Issue 12, 12101-1234.

Poprawe, M., (2015), A panel data analysis of the effect of corruption on tourism, Applied Economics 47,23, 2399-2412.

Robinson, P.M. (1994) Efficient tests of nonstationary hypotheses, Journal of the American Statistical Association 89, 1420-1437.

Rosselló-Nadal, J. and H.E. Jianan, (2020), Tourist arrivals versus tourist expenditures in modelling tourism demand, Tourism Economics, forthcoming.

Roselló-Nadal, J.R., A. Riera-Font and A. Sansó-Rosselló, (2004). The economic determinants of seasonal patterns. Annals of Tourism Research, 31(3), 697-711.

Saito, H. and J. Romão (2018). Seasonality and regional productivity in the Spanish accommodation sector. Tourism Management, 69, 180-188.

Saleh, A., R. Ihalanayake and R. Verma, (2011), Do External Shocks Have a Permanent or a Transitory Effect on Thailand's Tourism Industry?, Tourism Analysis 16, 4, 483-491.

Shareef, R. and M. McAleer, (2007), Modelling the uncertainty in monthly international tourist arrivals to the Maldives, Tourism Management 28, 1, 23-45.

Shen, S., G. Li and H. Song, 2009, Effect of seasonality treatment on the forecasting performance of tourism demand model, Tourism Economics 15, 4, 693-708. 
Song, H., and G. Li (2008). Tourism demand modelling and forecasting-A review of recent research. Tourism Management, 29(2), 203-220.

Song, H., Qiu, R. T., \& Park, J. (2019). A review of research on tourism demand forecasting. Annals of Tourism Research, 75, 338-362.

Tan, S-H. and S.K. Tan (2014), Are shocks to Singapore's tourist arrivals permanent or transitory? An application of stationarity test with structural breaks, Current Issues in Tourism Letters 17, 6.

Tang, C. F. (2011). Old wine in new bottles: Are Malaysia's tourism markets converging? Asia Pacific Journal of Tourism Research, 16(3), 263-272.

Tung, V.W.S., P. Lin, H.Q. Zhang and A. Zhao (2017), A framework of memory management and tourism experiences, Journal of Travel and Tourism Marketing 34, 7.

UNWTO (2014). UNWTO tourism highlights (2014 edition). Madrid: UNWTO.

Vergori, A. S. (2012). Forecasting tourism demand: the role of seasonality. Tourism Economics, 18(5), 915-930.

Visit Britain (2015). First-time and repeat visit to Britain. Foresight. Issue 149. (Accessed 16 April 2019) https://www.visitbritain.org/sites/default/files/vb-corporate/DocumentsLibrary/documents/foresight 149_-

frequency_of_inbound_tourism_to_britain_feb2017.pdf 
Figure 1: Time series plots: Original and logged transformed data

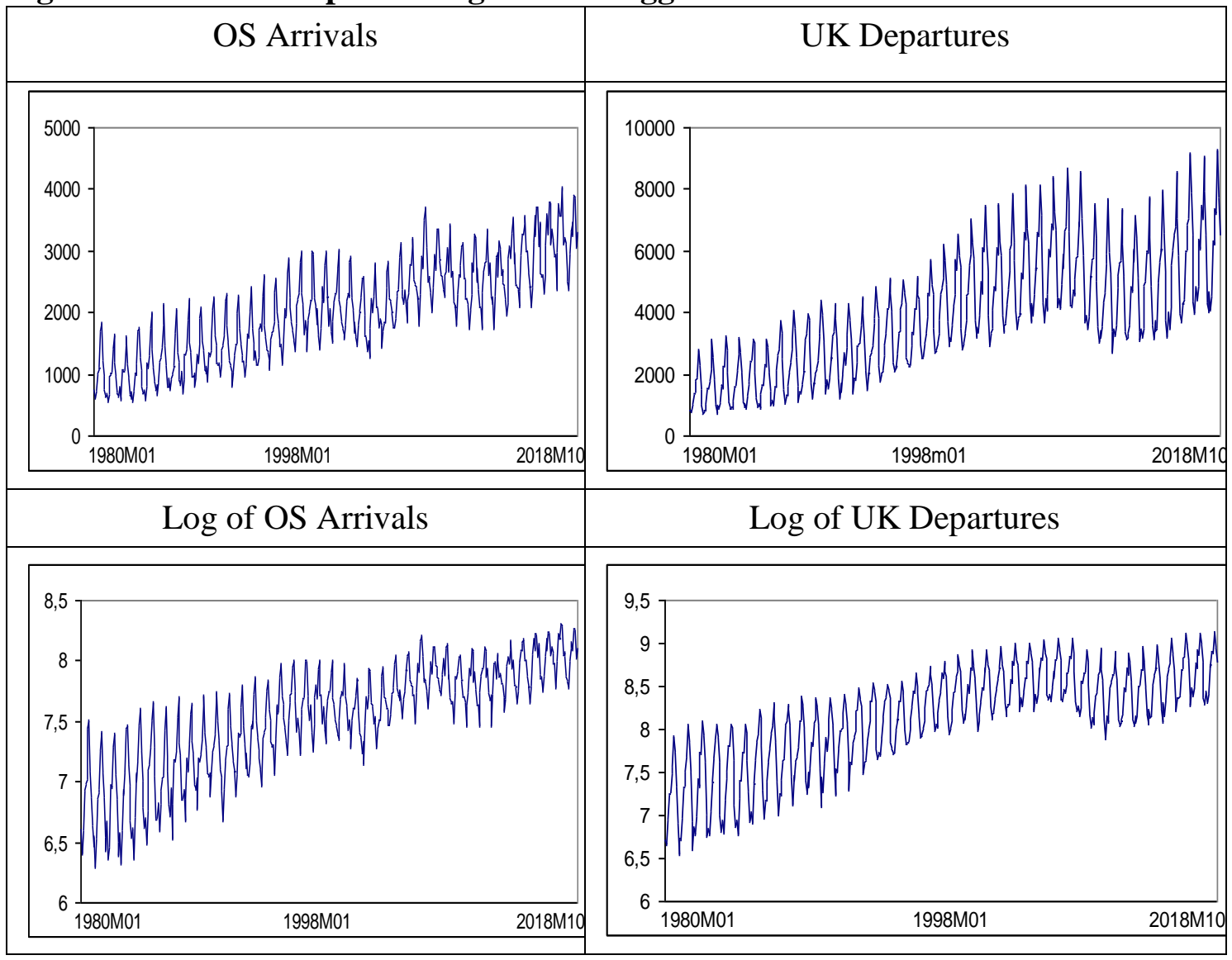


Table 1: Estimated values of $d$ based on the model given by equation (7)

\begin{tabular}{|c|c|c|c|}
\hline Series & No det. terms & A constant & A linear time trend \\
\hline OS Arrivals & $0.54(0.45,0.64)$ & $0.44(0.40,0.48)$ & $\mathbf{0 . 3 8}(\mathbf{0 . 3 2}, \mathbf{0 . 4 6})$ \\
\hline UK Departures & $0.60(0.52,0.68)$ & $0.54(0.49,0.60)$ & $\mathbf{0 . 5 2}(\mathbf{0 . 4 4 , 0 . 6 1 )}$ \\
\hline Log OS Arrivals & $0.98(0.91,1.07)$ & $0.45(0.41,0.50)$ & $\mathbf{0 . 4 3}(\mathbf{0 . 3 4}, \mathbf{0 . 5 3})$ \\
\hline Log UK Departures & $1.00(0.92,1.08)$ & $0.49(0.45,0.55)$ & $\mathbf{0 . 5 3}(\mathbf{0 . 3 8}, \mathbf{0 . 6 9})$ \\
\hline
\end{tabular}

Bold numbers indicate the selected specification. Those in parenthesis refer to the confidence intervals for $\mathrm{d}$ at the $95 \%$ level.

Table 2 Estimated coefficients in the model given by equation (7)

\begin{tabular}{|c|c|c|c|c|}
\hline Series & $\mathrm{d}$ & Constant & Time trend & Seas. $\rho_{\mathrm{s}}$ \\
\hline OS Arrivals & $0.38(0.32,0.46)$ & $855.50(5.14)$ & $5.044(7.89)$ & 0.911 \\
\hline UK Departures & $0.52(0.44,0.61)$ & $1163.74(1.85)$ & $11.230(3.63)$ & 0.966 \\
\hline Log OS Arrivals & $0.43(0.34,0.53)$ & $6.7844(64.47)$ & $0.0029(6.80)$ & 0.921 \\
\hline Log UK Departures & $0.53(0.38,0.69)$ & $7.0429(40.64)$ & $0.0038(4.38)$ & 0.963 \\
\hline
\end{tabular}


Figure 2: Time series plots: First seasonal differenced series

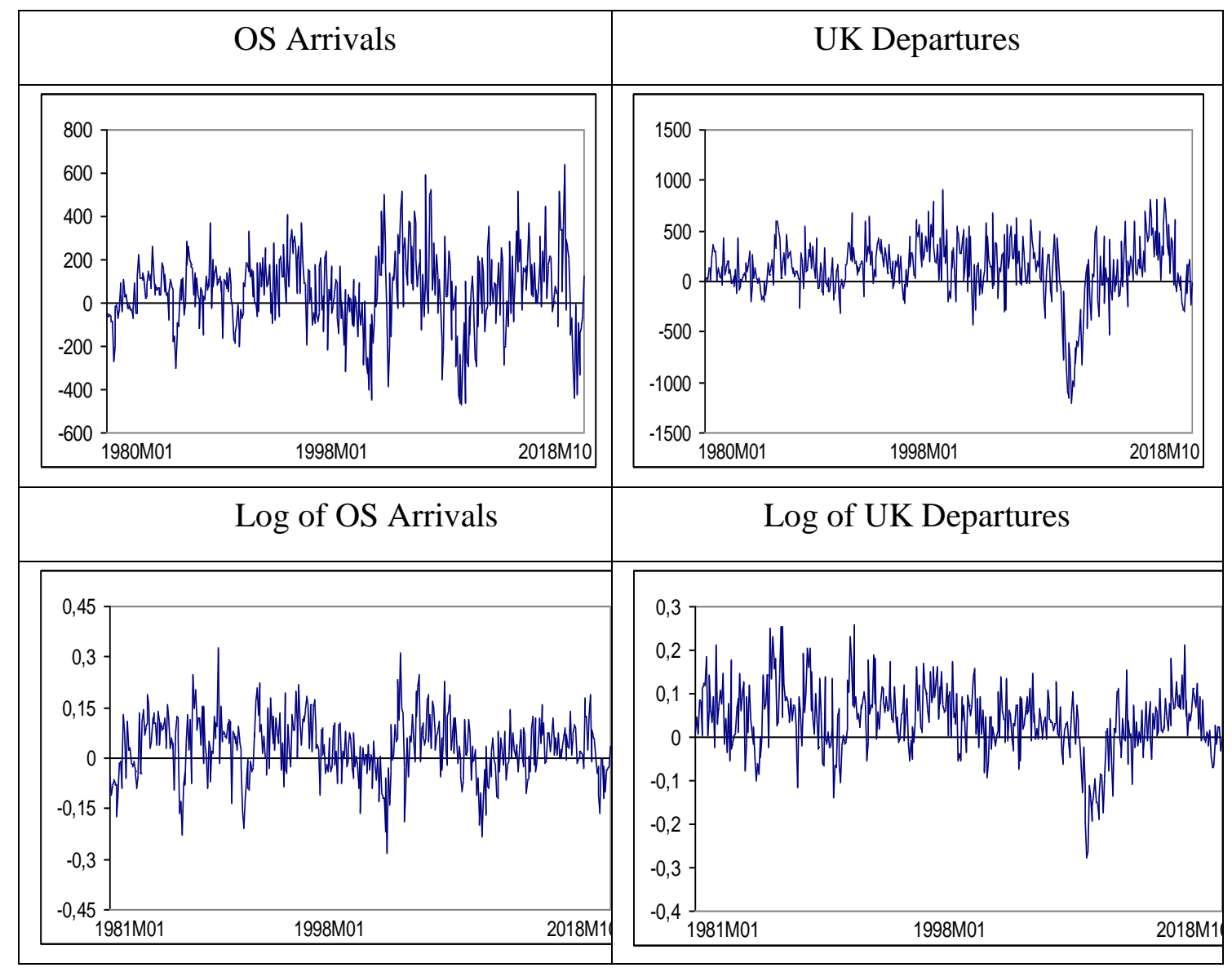


Table 3: Estimates of $d$ on the monthly differenced series using white noise errors

\begin{tabular}{|c|c|c|c|}
\hline & No det. terms & A constant & A linear time trend \\
\hline OS Arrivals & $\mathbf{0 . 3 5}(\mathbf{0 . 3 0}, \mathbf{0 . 4 2})$ & $0.35(0.30,0.42)$ & $0.35(0.30,0.42)$ \\
\hline UK Departures & $\mathbf{0 . 3 8}(\mathbf{0 . 3 4}, \mathbf{0 . 4 4})$ & $0.38(0.34,0.44)$ & $0.38(0.34,0.44)$ \\
\hline Log OS Arrivals & $\mathbf{0 . 3 6}(\mathbf{0 . 3 0}, \mathbf{0 . 4 2})$ & $0.36(0.30,0.42)$ & $0.36(0.39,0.42)$ \\
\hline Log UK Departures & $0.35(0.30,0.40)$ & $\mathbf{0 . 3 4}(\mathbf{0 . 2 9}, \mathbf{0 . 3 9})$ & $0.33(0.28,0.39)$ \\
\hline
\end{tabular}

Bold numbers indicate the selected specification. Those in parenthesis refer to the confidence intervals for $\mathrm{d}$ at the $95 \%$ level.

Table 4: Estimates of $d$ on the monthly differenced series using Bloomfield errors

\begin{tabular}{|c|c|c|c|}
\hline & No terms & A constant & A linear trend \\
\hline OS Arrivals & $\mathbf{0 . 4 7}(\mathbf{0 . 3 5}, \mathbf{0 . 6 3})$ & $0.47(0.35,0.63)$ & $0.48(0.35,0.63)$ \\
\hline UK Departures & $\mathbf{0 . 6 2}(\mathbf{0 . 5 1}, \mathbf{0 . 7 3})$ & $0.62(0.51,0.73)$ & $0.62(0.51,0.73)$ \\
\hline Log OS Arrivals & $\mathbf{0 . 4 8}(\mathbf{0 . 3 7}, \mathbf{0 . 6 4})$ & $0.49(0.37,0.64)$ & $0.50(0.37,0.64)$ \\
\hline Log UK Departures & $\mathbf{0 . 5 8}(\mathbf{0 . 4 6 , 0 . 6 9})$ & $0.56(0.44,0.70)$ & $0.55(0.44,0.70)$ \\
\hline
\end{tabular}

In bold, the selected models according to the deterministic terms. In parenthesis, the $95 \%$ confidence bands for the values of $d$. 